\title{
A MIMO Reversed Antenna Array Design for gsm1800/td-scdma/lte/wi-max/wiLan/wifi
}

\author{
Fang $X u^{1}$ and $M u J^{2}$ \\ ${ }^{1}$ Tianjin University, Tianjin 300072, China \\ ${ }^{2}$ Southeast University, Nanjing 211189, China \\ Correspondence should be addressed to Fang Xu; xf1988@tju.edu.cn
}

Received 30 July 2015; Accepted 18 August 2015

Academic Editor: Jaume Anguera

Copyright (c) 2015 F. Xu and M. Ju. This is an open access article distributed under the Creative Commons Attribution License, which permits unrestricted use, distribution, and reproduction in any medium, provided the original work is properly cited.

\begin{abstract}
A triband MIMO antenna used for gsm1800/td-scdma/lte/wi-max/wiLan/wifi has been proposed in this paper. The design with the size of $32 \mathrm{~m} * 73.6 \mathrm{~mm}$ is fabricated on FR4 substrate (thickness is $1.6 \mathrm{~mm}$ ). This antenna consists of two reversed monopole meandered radiators and defected ground structure which work together to achieve impedance match and enhance isolation for all operating bands. According to the subsequent measured results, the working frequency domains are at gsm1800 $(1.71 \mathrm{GHz}-$ $1.88 \mathrm{GHz})$, td-scdma $(1.88 \mathrm{GHz}-2.025 \mathrm{GHz})$, lte $(2.1-2.35,2.48-2.51)$, wi-max $(3.5 \mathrm{GHz}, 5.5 \mathrm{GHz})$, wiLan $(5.725 \mathrm{GHz}-5.8 \mathrm{GHz})$, and wifi $(5.8 \mathrm{GHz}-5.88 \mathrm{GHz})$ approximately. Besides, the measured radiation patterns (gain total) are also well at these working frequency domains and the omnidirectional performance has been achieved for the reversed MIMO antenna array. Furthermore, the realized isolation is more than $15 \mathrm{~dB}, 24.2 \mathrm{~dB}$, and $22 \mathrm{~dB}$ at the first, the second, and the third working frequency band, respectively.
\end{abstract}

\section{Introduction}

Multi-input, multioutput is a technology in wireless communication which can transmit information with high data rate and increase channel capacity with the same channel bandwidth. So the MIMO technology is very important for the next generation wireless communication. With the wireless technology development, the MIMO antenna has been required to have multiband performance, simple structure, relative small size, light weight, and low cost to be easily integrated with complex multifunction RF circuit. Recently, there are several research works focusing on the MIMO antennas, such as the MIMO antenna with $\mathrm{H}$-shaped directive antenna [1], but it can only operate at one frequency band from $4.5 \mathrm{GHz}$ to $6.2 \mathrm{GHz}$ and the isolation is not good. In the literature $[2,3]$ the MIMO antennas show good performance on compact size. However, the isolation is relatively poor and there are few working coverages. Other MIMO antenna designs for handset application [4-6] are presented for excellent performance of isolation while the size is relatively big. For [7], a simpler MIMO antenna has been proposed whereas the achieved isolation is less than
$12 \mathrm{~dB}$ for most of the frequency domain and should be improved. The high-isolation (more than $17 \mathrm{~dB}$ ) and singleband MIMO antenna with wide coverage has been presented in [8]. Nevertheless, it is possible to be interfered by useless signal and the size is not suitable for handset application. In this paper, the novel tri-band MIMO design on the FR4 substrate has been presented.There are two reversed monopole radiators diagonally on the substrate for MIMO performance. The monopole radiator is proposed in my another paper which is now under review by microwave journal. There are two reversed monopole radiators located diagonally on the substrate for MIMO performance. This design can cover three frequency bands simultaneously based on the measured/simulated results and the isolation is also good compared to the listed references. Meanwhile, the planar area size is eligible for handset devices application.

\section{Multiband Antenna Design}

As is shown in Figure 1 there are two layers for the MIMO antenna in this paper. The dendritic meandered microstrip is 


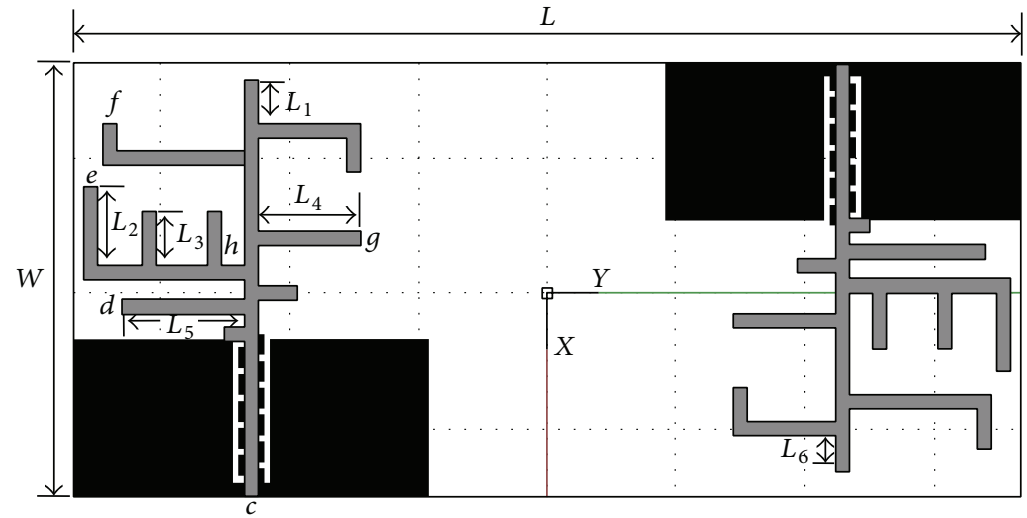

(a)

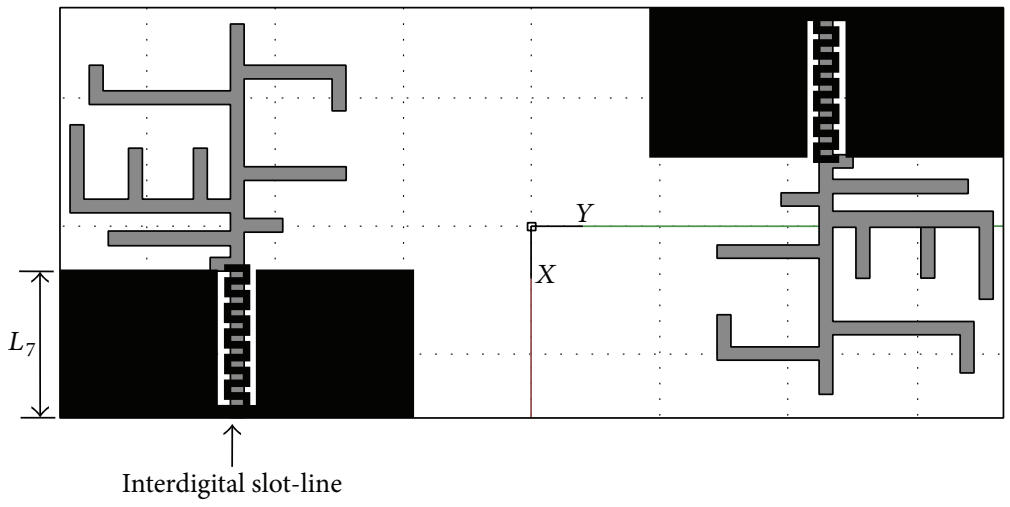

(b)

Figure 1: The proposed antenna in this paper. (a) The top view. (b) The bottom view.

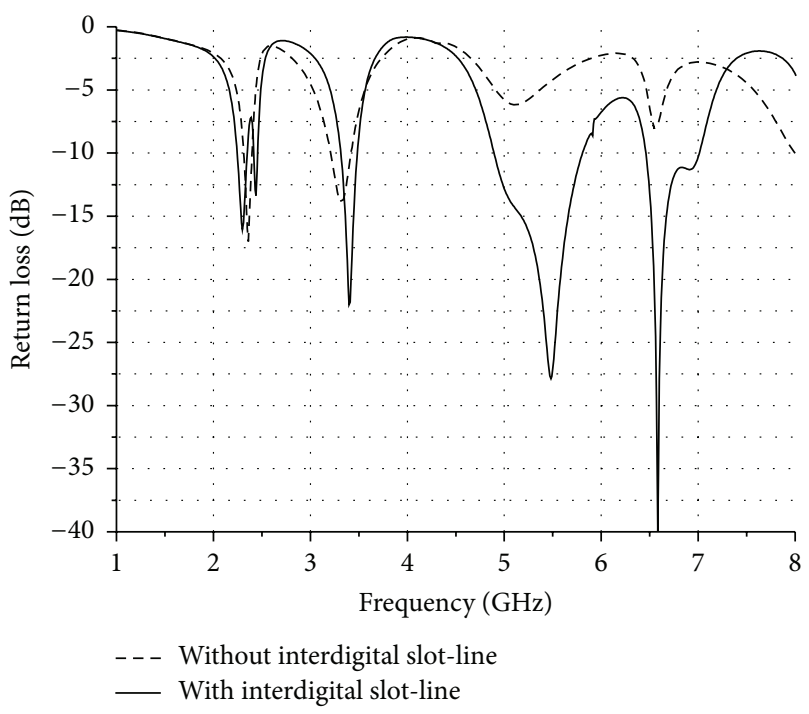

FIGURE 2: The simulated results for the proposed antenna and design without interdigital slot-line.

located on the top layer and the reversed interdigital slot-line can be seen from the bottom view. On the other hand, the size of this antenna is $32 \mathrm{~mm} * 73.6 \mathrm{~mm} * 1.6 \mathrm{~mm}$ so that this

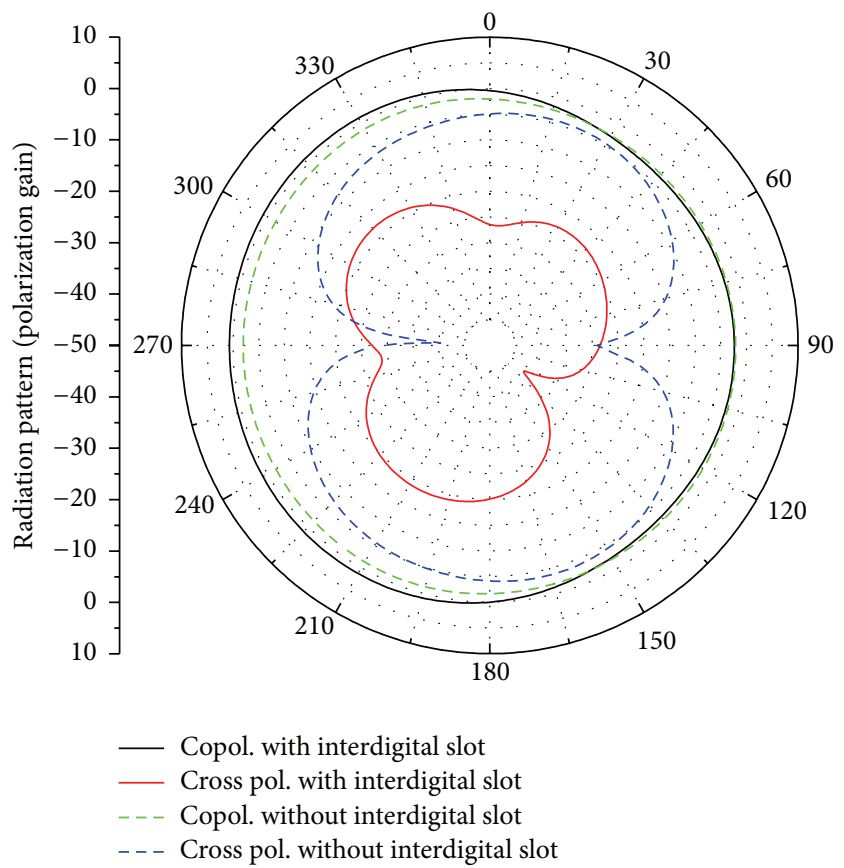

FIGURE 3: The copolarization and cross polarization with interdigital slot-line and without interdigital slot-line $(\mathrm{phi}=90)$ at $2.3 \mathrm{GHz}$. 


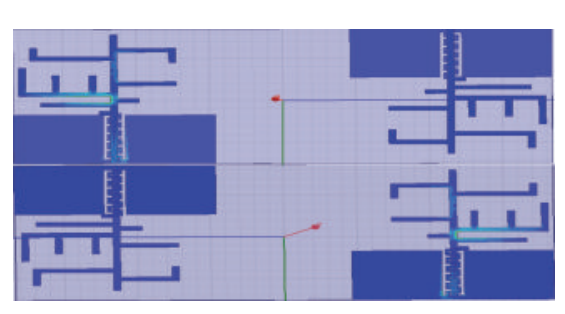

(a)

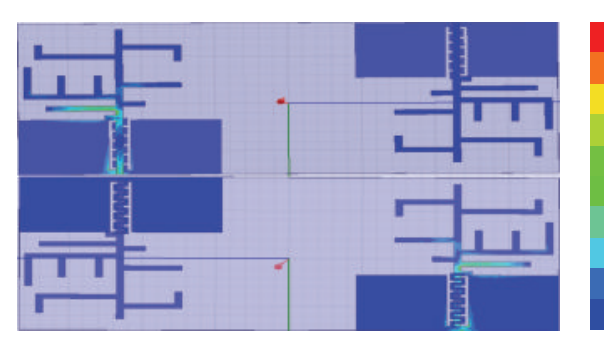

(c)

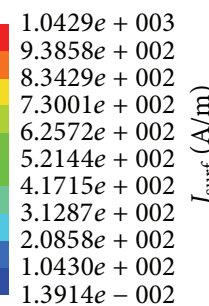

$1.0430 e+002$

$1.3914 e-002$

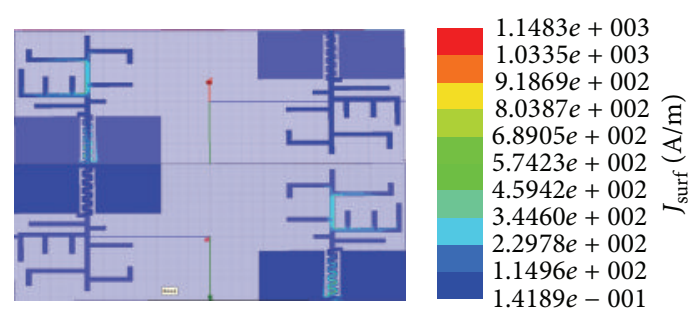

(b)

$4.5029 e+002$

$4.0526 e+002$

$3.6023 e+002$

$3.1520 e+002$

$2.7017 e+002 \Xi$

$2.2515 e+002 \unlhd$

$1.8012 e+002$

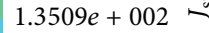

$9.0064 e+001$

$4.5036 e+001$

$8.2504 e-003$

MIMO antenna. (a) $2.3 \mathrm{GHz}$. (b) $3.45 \mathrm{GHz}$. (c) $5.4 \mathrm{GHz}$.

Figure 4: The simulated electric current distribution of the MIMO antenna. (a) $2.3 \mathrm{GHz}$. (b) $3.45 \mathrm{GHz}$. (c) $5.4 \mathrm{GHz}$.

TABLE 1: The detailed size of this design.

\begin{tabular}{ccccccccc}
\hline$L 1$ & $L 2$ & $L 3$ & $L 4$ & $L 5$ & $L 6$ & $L 7$ & $L$ & $W$ \\
\hline 2.2 & 5.8 & 4 & 8 & 9.5 & 2.2 & 11.6 & 73.6 & 32 \\
\hline
\end{tabular}

design can be used for the wireless handset application. The detailed size of the antenna is presented in Table 1 (unit: $\mathrm{mm}$ ).

The substrate is FR4 (thickness is $1.6 \mathrm{~mm}$ ) with a relative permittivity of 4.4 and loss tangent of 0.02 . It can be easily known that the structure is simple compared to other MIMO antennas with the same multiband function. The difficulty for MIMO multiband antenna design is to generate multipaths for resonating electric current at multifrequency bands. The two linear polarization radiators located diagonally at substrate can generate three primary resonating current paths below $6 \mathrm{GHz}$ for the multiband performance. The first and second band are created by the top-side dendritic microstrip by realizing the impedance match. The interdigital slot-line can excite the third-band performance and enhance the impedance match at all bands which can be inferred from Figure 2. Besides, interdigital slot-line proposed in my other submitted paper mentioned in Introduction will provide the meandered path for electric current at the first band to increase the cross polarization ratio for diversion transmission/reception application in mobile communication (lte/tdscdma) which can be summarized from Figure 3. These can be also analyzed from Figure 4 where there is distributed resonating electric current around the interdigital slot-line at all bands especially for the first and third band. This demonstrates that the performance of antenna can be influenced and adjusted by the defected ground structure. The resonating electric current can flow on the meandered path imbedded in the interdigital slot-line at the first frequency domain so that the effective radiation length can be increased to $0.14 \lambda$ and the polarization electromagnetic fields should be counteracted with each other due to the different current direction. For the second band, the electric current mainly appears on Path $d$ to $h(d, h$ are marked in Figure 1$)$ that is as long as $0.132 \lambda$ for radiation. When the frequency is moved to the third band electric current with about primary $0.161 \lambda$ radiation length will not only activate on the top-side but also flow below the interdigital slot-line which shows the interdigital slot-line is important to achieve impedance match at this band for antenna too.

Furthermore, the reversed structure will weaken the mutual coupling effect caused by the defected ground structure between the two monopole radiators. So the structure can enhance the mutual isolation of the two radiators.

The return loss can be derived as the following equation:

$$
S_{11}=\frac{Z_{0}-Z_{\text {in }}}{Z_{0}+Z_{\text {in }}}
$$

where $Z_{0}$ is the port impedance and $Z_{\text {in }}$ is the equivalent input impedance of the antenna. When the port impedance is matched to antenna impedance at some frequencies the signal will be transmitted/received with very weak reflection. As for this design, most of the electric current will flow through the corresponding three equivalent paths in the working frequency domains. So the impedance of the equivalent resonating path should be thought to be approximate to $Z_{0}$ at corresponding frequencies $\left(Z_{0} \approx Z_{\text {in }}\right)$. The equivalent impedance of the top-side radiator which is the shunt and series connections of several microstrips on each path can be obtained based on the basic impedance formula of microstrip [10]:

$$
Z_{\text {microstrip }} \approx \frac{87}{\sqrt{\varepsilon+1.41}} \ln \left(\frac{5.98 H}{0.8 W+L}\right),
$$

where $\varepsilon$ is the dielectric constant of the substrate, $H$ is the thickness, $W$ is the width of microstrip, and $L$ is the total length of microstrip. 

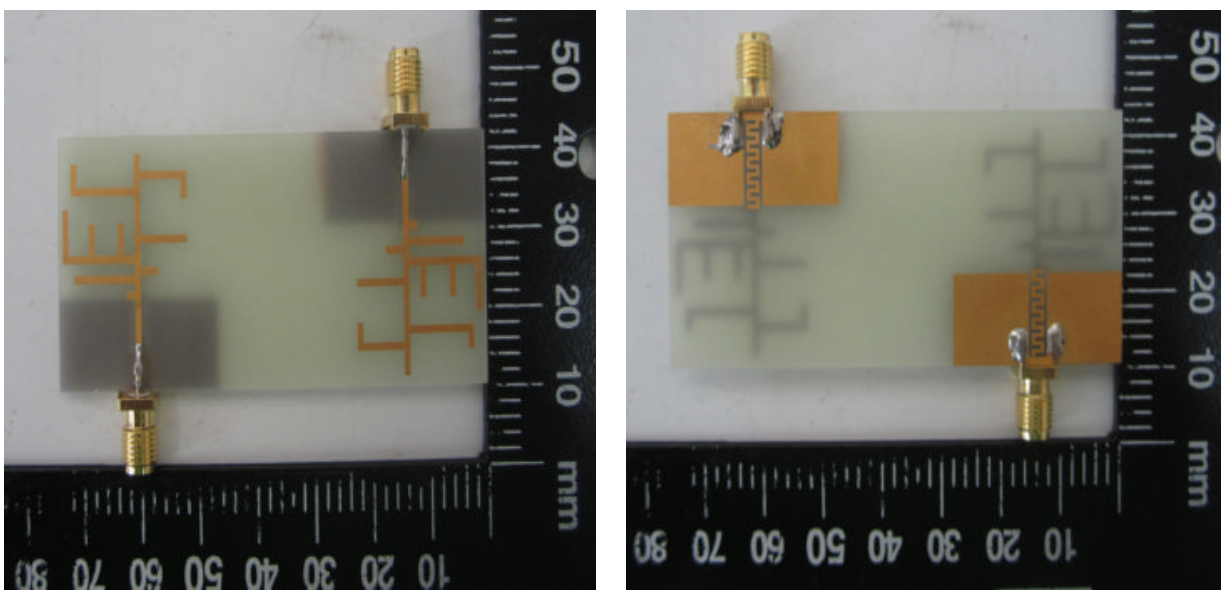

FIgURE 5: The fabricated MIMO antenna.

Except for the microstrip part, the coupling capacitance which is influenced by defected ground structure and relative location of two radiators should also be considered into the whole path. The equivalent impedance of capacitance is

$$
Z_{\text {capacitance-equivalent }}=\frac{1}{j \omega C_{1}}+\frac{1}{j \omega C_{2}}, \quad \omega=2 \pi f,
$$

where $C_{1}$ is the coupling capacitance between top-side microstrip and ground (influenced by interdigital slot) while $\mathrm{C}_{2}$ is the coupling capacitance between two monopole radiators. According to the analysis above, impedance of each path should be expressed as sum of $Z_{\text {capacitance-equivalent }}$ and $Z_{\text {top-radiator }}$ So the working frequencies can be calculated and adjusted through the top-side microstrip and DGS (defected ground structure) at bottom side and locations of two radiators.

Consequently, the defected ground structure and the dendritic reverse radiators on top can work together to excite the corresponding frequency bands at $2.1 \mathrm{GHz} / 3.5 \mathrm{GHz} / 5.4 \mathrm{GHz}$ in simulation results.

\section{Measured Results Analysis}

The fabricated antenna has been shown in Figure 5. As can be known the size of this two-layer planar MIMO antenna is $32 \mathrm{~mm} * 73.6 \mathrm{~mm} * 1.6 \mathrm{~mm}$ and it has been measured for return loss and radiation pattern but there is some discrepancy due to the inaccuracy of simulation and measurement, use of SMA connector, fabrication limitation, and some other random reasons. In addition, the comparison table between this design and some references is provided to prove the good performance of this design on relative compact size, multiband performance, high isolation level, and so on. The measured results tell us that the proposed design can work at gsm1800 $(1.71 \mathrm{GHz}-$ $1.88 \mathrm{GHz}) /$ td-scdma $(1.88 \mathrm{GHz}-2.025 \mathrm{GHz}) /$ lte $(2.025 \mathrm{GHz}-$ $2.35 \mathrm{GHz}) /$ wi-max $(3.5 \mathrm{GHz}, 5.5 \mathrm{GHz}) /$ wiLan $(5.725 \mathrm{GHz}-$ $5.8 \mathrm{GHz}) /$ wifi $(5.8 \mathrm{GHz}-5.88 \mathrm{GHz})$ simultaneously. The simulation and measurement presented in Figure 6 indicate the isolation is more than $15 \mathrm{~dB}, 24.2 \mathrm{~dB}$, and $22 \mathrm{~dB}$ for the first, second, and third working frequency domain, respectively.

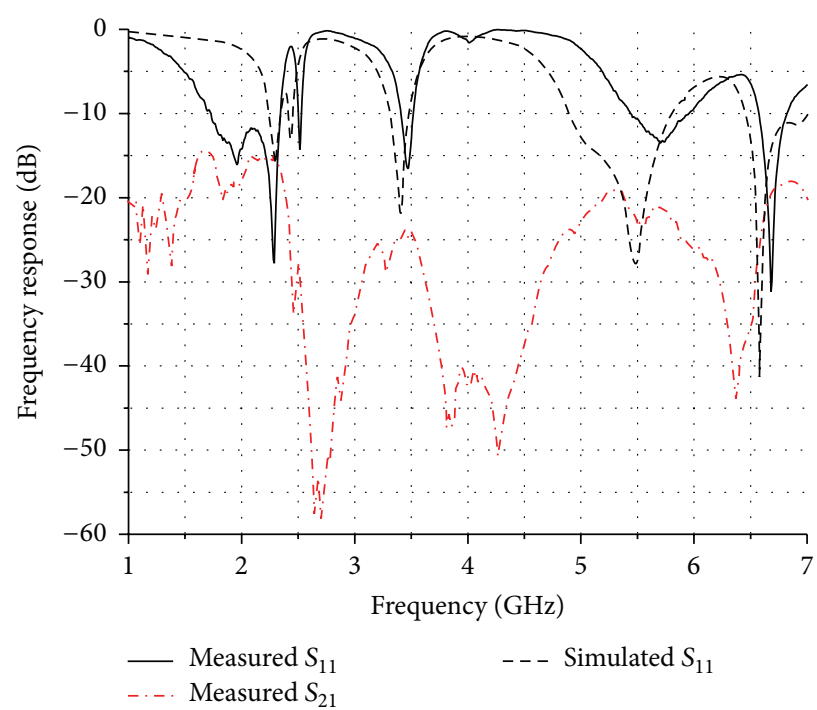

Figure 6: The measured $S_{11}, S_{21}$ and simulated $S_{11}$.

Furthermore, the radiation pattern at three frequency bands is well qualified in Figure 7. The measured radiation pattern can verify the omnidirectional performance of the proposed MIMO antenna in the three frequency bands. Besides, the measured peak gain totals in Table 2 are all bigger than $0 \mathrm{dBi}$ which demonstrate that the radiation efficiency is greater than the ideal radiation antenna so the energy $(-20 \mathrm{~dB}$ delivered to antenna in this experiment) should be radiated out with relative high efficiency. At last, the comparison information between this paper and other references is presented in Table 2. It is easily inferred from the table that the antenna in this paper has advantages in gain total, relative compact size, multiband working performance, and relative high isolation level compared to previous works. Last but not least, the enveloped correlation can also be derived by [11]

$$
\rho_{e}=\frac{\left|S_{11} \times S_{12}+S_{21} \times S_{22}\right|^{2}}{\left(1-\left|S_{11}\right|^{2}-\left|S_{21}\right|^{2}\right)\left(1-\left|S_{22}\right|^{2}-\left|S_{12}\right|^{2}\right)} \text {. }
$$




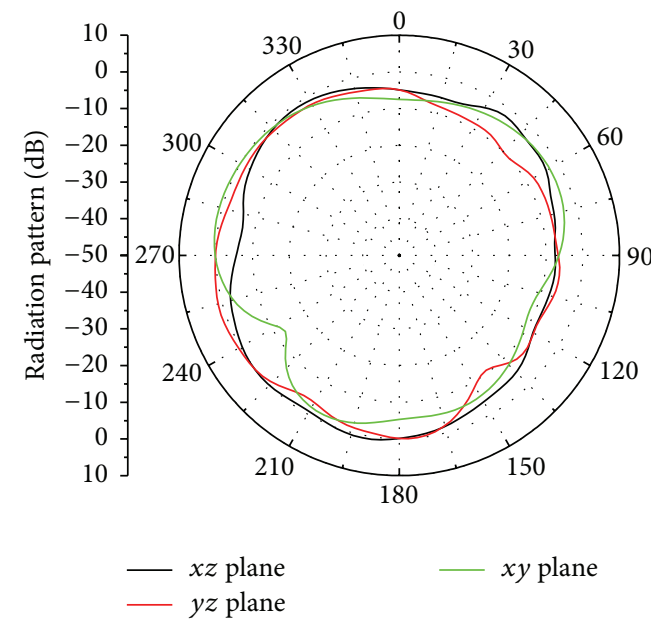

(a)

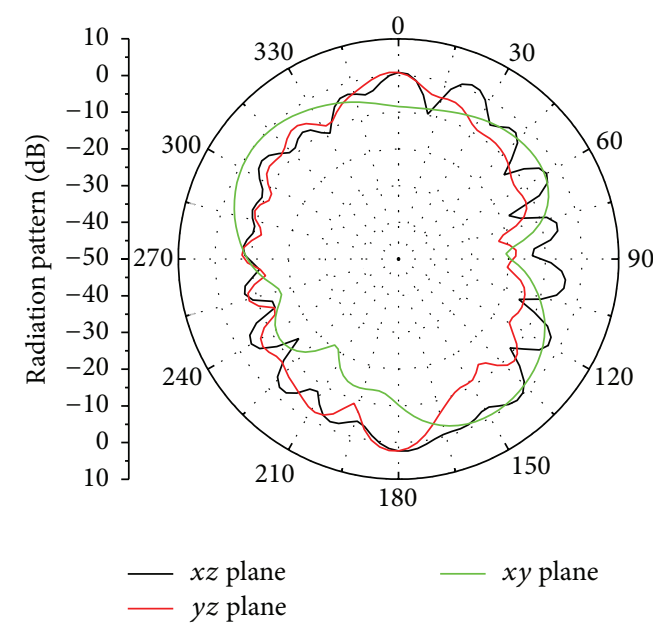

(c)

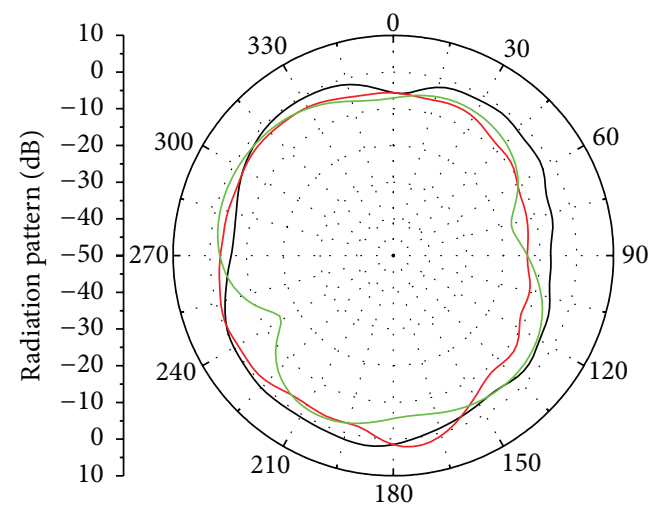

$-x z$ plane
$-y z$ plane

_ $x y$ plane

(b)

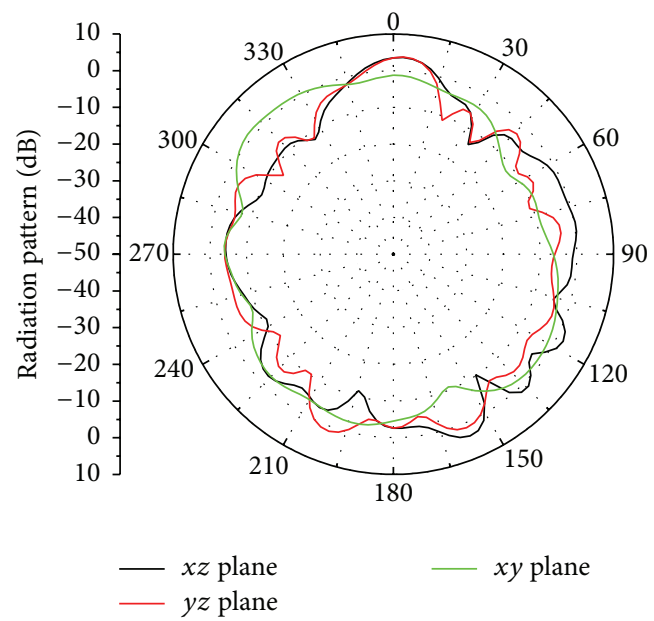

(d)

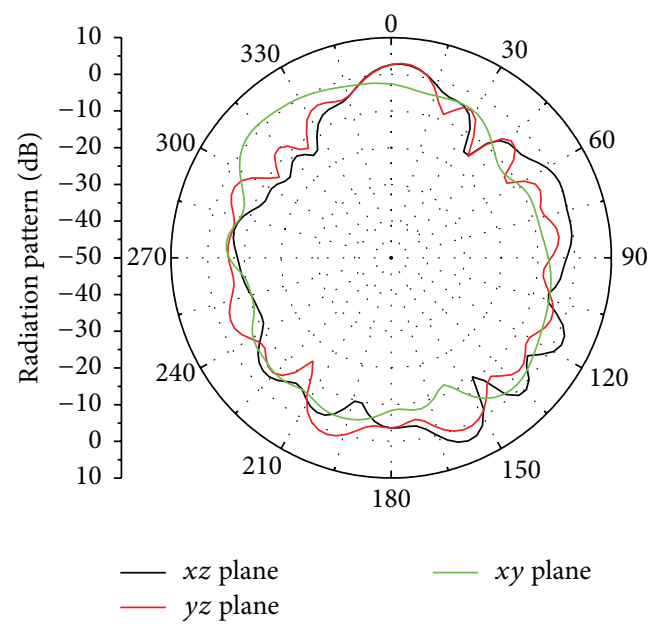

(e)

Figure 7: The measured radiation pattern of the MIMO antenna. (a) $1.98 \mathrm{GHz}$. (b) $2.14 \mathrm{GHz}$. (c) $3.5 \mathrm{GHz}$. (d) $5.75 \mathrm{GHz}$. (e) $5.85 \mathrm{GHz}$. 
TABLE 2: The comparison of the performances between this paper and some references.

\begin{tabular}{|c|c|c|c|}
\hline Refs & Planar area size $(\mathrm{mm} * \mathrm{~mm})$ & Measured peak gain $(\mathrm{dBi})$ & Isolation $(\mathrm{dB})$ \\
\hline $\begin{array}{l}\text { This } \\
\text { paper }\end{array}$ & $32 * 73.6$ (triband) & $\begin{array}{l}2.54(1.81 \mathrm{GHz}) / 1.97(1.98 \mathrm{GHz}) / 3.43 \\
(2.14 \mathrm{GHz}) / 3.47(3.5 \mathrm{GHz}) / 5.99(5.75 \mathrm{GHz}) / 5.55 \\
(5.85 \mathrm{GHz})\end{array}$ & $\begin{array}{l}\geq 14.6 \mathrm{~dB}(1 \mathrm{st} \text { band }) / \geq 24.2 \mathrm{~dB} \\
(2 \mathrm{nd} \text { band }) / \geq 22 \mathrm{~dB} \text { ( } 3 \text { rd band })\end{array}$ \\
\hline$[1]$ & $42 * 42$ (single-band) & $5.2(5.45 \mathrm{GHz})$ & $\geq 14 \mathrm{~dB}$ (in working band) \\
\hline$[4]$ & $110 * 65$ (single-band) & $1.07(1.9 \mathrm{GHz}) / 1.53(2.1 \mathrm{GHz}) / 2.73(2.45 \mathrm{GHz})$ & $\geq 15 \mathrm{~dB}$ (in working band) \\
\hline$[7]$ & $60 * 120($ dual-band $)$ & $0(0.9 \mathrm{GHz}) / 4(2.5 \mathrm{GHz})$ & $\begin{array}{l}\geq 12 \mathrm{~dB} \text { (1st band)/ } \geq 11 \mathrm{~dB} \text { (2nd } \\
\text { band) }\end{array}$ \\
\hline$[9]$ & $35 * 112.5$ (dual-band) & $2.01(0.75 \mathrm{GHz}) / 6.3(2.15 \mathrm{GHz})$ & $\begin{array}{l}\geq 9.5 \mathrm{~dB} \text { (1st band) } / \geq 12 \mathrm{~dB} \\
\text { ( } 2 \text { nd band) }\end{array}$ \\
\hline
\end{tabular}

The calculated enveloped correlation using measured data is less than 0.001 at all operating bands. This is very well for MIMO application. In a word, the measured results of this antenna show the qualified performance for most wireless terminus applications.

\section{Conclusion}

In this paper, a novel MIMO antenna array with two monopole antennas for gsm1800, td-scdma, wi-max, wiLan, wifi is designed and fabricated. The antenna with three main electric current resonating paths consists of dendritic radiator on top and bottom-layer interdigital slot-line. The size of the proposed MIMO antenna is $0.21 \lambda * 0.48 \lambda * 0.01 \lambda(\lambda$ is the wavelength at $1.98 \mathrm{GHz}$ based on the experimental results) that is eligible for handset device application. The simulated and measured results also prove the design is feasible. Meanwhile, the peak gain and gain total is well which demonstrate the approximate omnidirectional performance and high radiation efficiency for the antenna. Finally, the structure of the designed MIMO array with three bands in this letter is simple and very easy to be implemented so that it can be widely used in wireless communication systems.

\section{Disclosure}

$\mathrm{Mu} \mathrm{Ju}$ is a coauthor.

\section{Conflict of Interests}

The authors declare that there is no conflict of interests regarding the publication of this paper.

\section{References}

[1] Y. Luo, Q.-X. Chu, J.-F. Li, and Y.-T. Wu, "A planar Hshaped directive antenna and its application in compact MIMO antenna," IEEE Transactions on Antennas and Propagation, vol. 61, no. 9, pp. 4810-4814, 2013.

[2] L. Liu, S. W. Cheung, and T. I. Yuk, "Compact MIMO antenna for portable UWB applications with band-notched characteristic," IEEE Transactions on Antennas and Propagation, vol. 63, no. 5, pp. 1917-1924, 2015.

[3] K. Kahng, I. Yang, S. Kahng, J. Anguera, and J. Y. Lee, "Design of four MIMO handset antennas," in Proceedings of the 7th
European Conference on Antennas and Propagation (EuCAP '13), pp. 723-725, April 2013.

[4] S. Shoaib, I. Shoaib, N. Shoaib, X. Chen, and C. G. Parini, "MIMO antennas for mobile handsets," IEEE Antennas and Wireless Propagation Letters, vol. 14, pp. 799-802, 2015.

[5] X. Chen, S. Shoaib, I. Shoaib et al., "MIMO antennas for mobile handsets," in Proceedings of the 3rd Asia-Pacific Conference on Antennas and Propagation (APCAP '14), pp. 412-414, July 2014.

[6] S. Shoaib, I. Shoaib, N. Shoaib, X. Chen, and C. G. Parini, "Design and performance study of a dual-element multiband printed monopole antenna array for MIMO terminals," IEEE Antennas and Wireless Propagation Letters, vol. 13, pp. 329-332, 2014.

[7] Y.-L. Ban, Z.-X. Chen, Z. Chen, K. Kang, and J. L.-W. Li, “Decoupled hepta-band antenna array for WWAN/LTE smartphone applications," IEEE Antennas and Wireless Propagation Letters, vol. 13, pp. 999-1002, 2014.

[8] M. Sonkki, D. Pfeil, V. Hovinen, and K. R. Dandekar, "Wideband planar four-element linear antenna array," IEEE Antennas and Wireless Propagation Letters, vol. 13, pp. 1663-1666, 2014.

[9] Y.-J. Ren, "Ceramic based small LTE MIMO handset antenna," IEEE Transactions on Antennas and Propagation, vol. 61, no. 2, pp. 934-938, 2013.

[10] J. S. Hong, Microstrip Filters for RF/Microwave Applications, Wiley, 2011.

[11] A. Sanada, M. Kimura, I. Awai, C. Caloz, and T. Itoh, "A planar zeroth-order resonator antenna using a left handed transmission line," in Proceedings of the 34th European Microwave Conference, pp. 1341-1344, October 2004. 

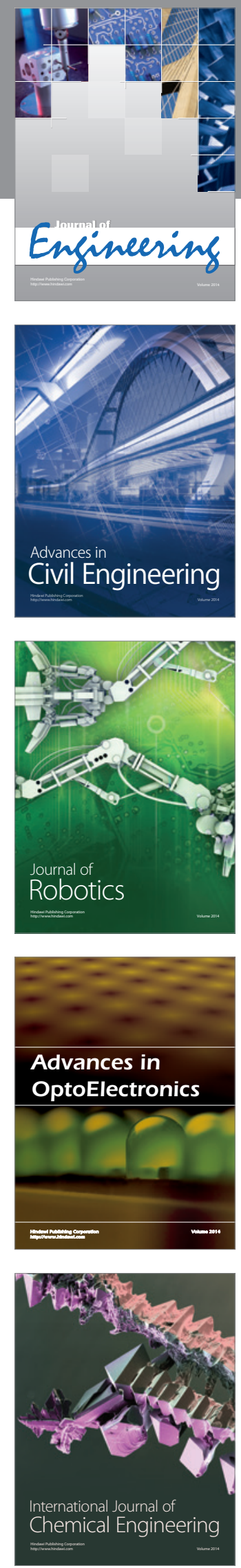

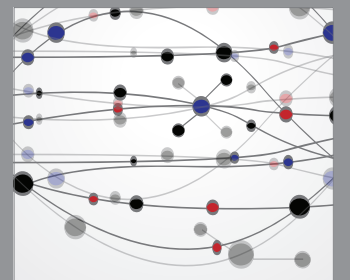

The Scientific World Journal
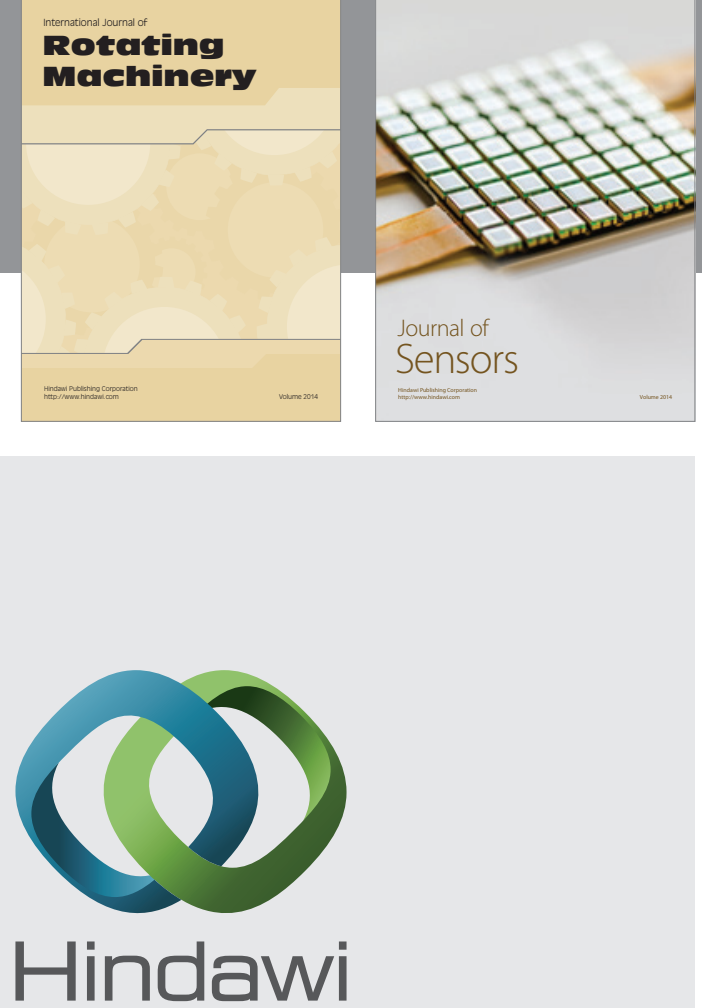

Submit your manuscripts at http://www.hindawi.com
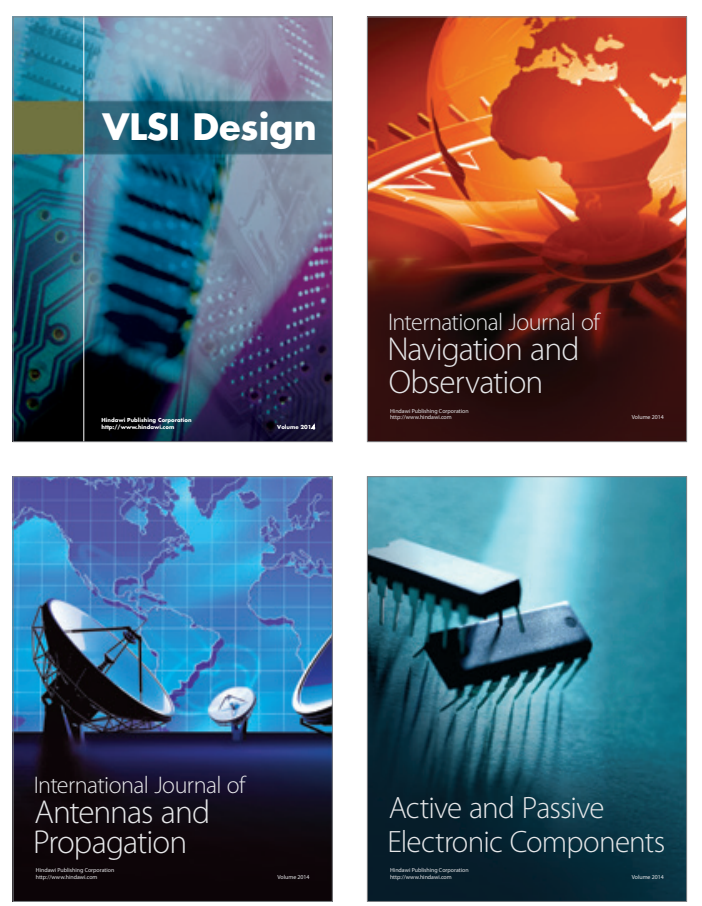
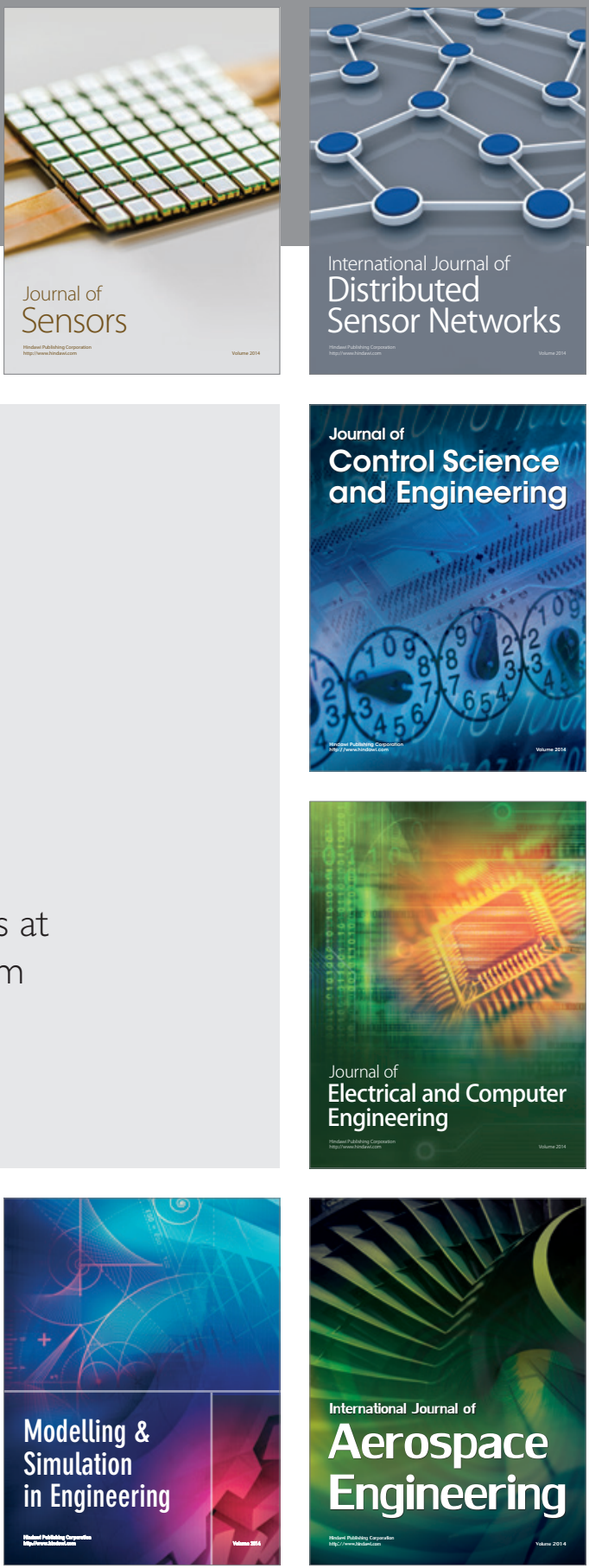

Journal of

Control Science

and Engineering
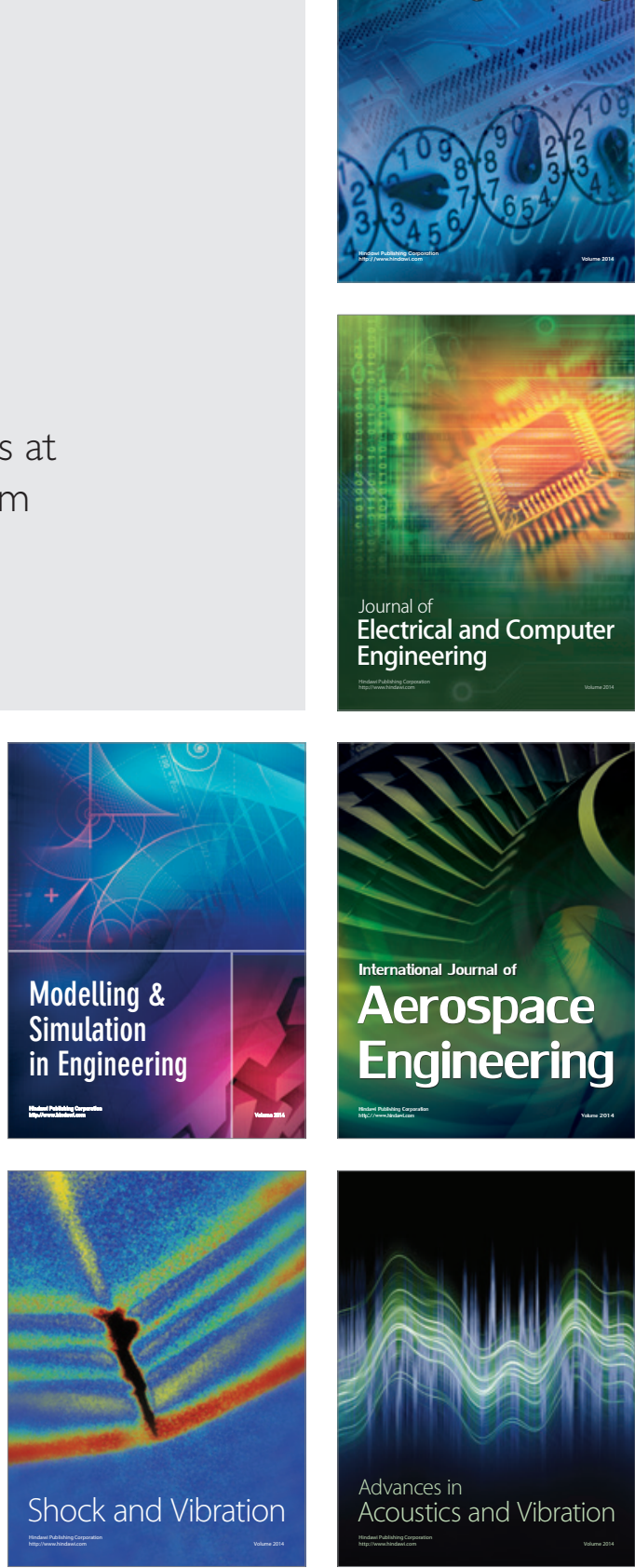